\title{
Kinetics of plasma procalcitonin during the acute phase of severe traumatic brain injury
}

\author{
H. mehdi $^{1}$, B. A. Eya ${ }^{1}$, B. S. Youssef ${ }^{1}$ \\ 1 trauma center - tunis (Tunisia)
}

Background and Goal of Study.Procalcitonin is recognized as a biomarker of inflammation and sepsis. plasma levels were found after major surgery and polytrauma. The aim of our study is to evaluate the kinetics of plasma procalcitonin during the acute phase of severe trauma.

Materials and Methods: 78 Severe trauma are included in a prospective study .were excluded from the study those who had a serious medical history that could interfere with the assay of procalcitonin or other acute pathologies may alter the procalcitonin. It was noted severity scores (IGSHO / H48, ISS, BSC) and the kinetics of white blood cells, CRP, creatinine and procalcitonémie (ELISA [Brahms $\left.{ }^{\circledR}\right]$ ). Venous samples were taken at J1,2,3 and $\mathrm{J7}$.

Results and Discussion:The average PCT at day 2 was $14.3 \pm 7,6 \mu \mathrm{g} /$ I for patients with an ISS score at admission $\geq 25$ versus $3.6 \pm 2,2 \mu \mathrm{g} /$ I for those with ISS $<25(p=0.022)$. The average PCT at day 7 for patients with an ISS score at admission ISS $\geq 25$ was $8.5 \pm 4,1 \mu \mathrm{g} /$ I versus $0.6 \pm 0,38 \mu \mathrm{g} /$ I for those with ISS $<25(p=0.031)$.

\begin{tabular}{|l|l|l|l|}
\hline & dead & favorable & $p$ \\
\hline PCT 2 & $8,5 \pm 5,8$ & $6,7 \pm 1,4$ & 0.02 \\
\hline PCT 3 & $9,1 \pm 6,2$ & $7,6 \pm 1,5$ & 0.016 \\
\hline PCT 7 & $31,5 \pm 7,5$ & $19,1 \pm 4,2$ & 0.008 \\
\hline
\end{tabular}

Conclusion:The significant increase of the kinetics of blood Procalcitonin seems to be a predictive factor of gravity

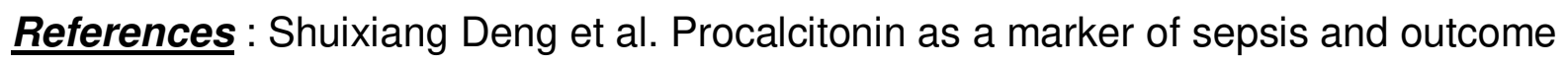


